\title{
Co-integration Analysis of the Innovation Input and Performance of China's High-tech Industries
}

\author{
Kaiming Tan \\ School of Economics and Management \\ Dalian University \\ Dalian, China
}

\author{
Shihong Wei \\ School of Economics and Management \\ Dalian University \\ Dalian, China
}

\begin{abstract}
This paper studies the relationship between the innovation input and performance of China's high-tech industries by making use of the indicator statistics concerning high-tech industries and co-integration analysis. Results show that the output value of new products has a long-term equilibrium relationship with internal $R \& D$ spending, the fulltime equivalent (FTE) of R\&D personnel and the spending on technical transformation; the results of the Granger Causality Test show that the change in the output value of new products leads to the changes in internal R\&D spending, the FTE of R\&D personnel and the spending on technical transformation.
\end{abstract}

Keywords-DEA method; innovation input; innovation performance; co-integration analysis

\section{INTRODUCTION}

Innovation serves as an important means for enterprises to enhance core competitiveness, gain competitive advantages and improve performance. High-tech industries involve a high input of innovation. Thus, the question of whether high innovation input leads to high performance has caught the attention of more and more scholars in recent years. He Qingfeng (2009) conducted an empirical research on the quantitative relationship among direct human-capital investment, R\&D investment and innovation performance of the scientific and technological activities in China ${ }^{[1]}$. Sun Wei (2009) utilized the panel data of 17 Chinese high-tech industries between 1996 and 2007 and chose the Malmquist two-step approach to conduct an empirical analysis of the impact of different R\&D investment subjects on the innovation performance, decomposition and variations of high-tech industries ${ }^{[2]}$. Li Hui (2009) adopted the panel-data co-integration method to analyze the impact of funding structure on R\&D performance of the high-tech industries in 20 Chinese regions ${ }^{[3]}$. Zhu Weiping and Lun Rui (2004) used their empirical analysis to point out the insignificant correlation among $R \& D$ funding, input of $R \& D$ staff and corporate performance in Chinese high-tech enterprises ${ }^{[4]}$. Cheng Hua (2006), based on analysis of the data related to large and medium-sized industrial enterprises, reached the conclusion that direct government appropriation had an indirect and slow impact on corporate innovation performance and that loans from financial agencies had an insignificant effect on corporate innovation performance ${ }^{[5]}$.

Existing researches have various choices of indicator systems, with some indicators being too simple and the choice of evaluation methods being different. With that in mind, this paper selects the sales revenue of new products as the indicator of innovation performance, with the indicators of innovation input being internal R\&D spending, the fulltime equivalent (FTE) of R\&D personnel and the spending on technical transformation. The paper applies co-integration analysis to explore the relationship between innovation input and performance of Chinese high-tech industries, in a bid to raise targeted strategies to improve the output efficiency of innovation input.

\section{SELECTION OF INDICATORS AND EMPIRICAL ANALYSIS}

\section{A. Selection of Indicators and Data Description}

In terms of innovative input, scholars usually select R\&D spending and the input of R\&D staff as the indicators. This paper also selects internal R\&D spending and the FTE of R\&D personnel respectively to gauge innovation funding and the input of innovation staff. Except R\&D investment, part of innovation input is used for technical transformation. Technical transformation refers that enterprises, based on the scientific and technological progress, apply scientific and technological achievements to various fields (such as products, equipment and processes) and replace outdated technology and equipment with advanced ones to expand connotation-oriented reproduction, improve product quality and achieve product update, energy saving, consumption reduction and all-round improvement of the comprehensive economic efficiency. Therefore, technical transformation is significant in improving corporate innovation performance; the spending on technical transformation has a direct impact on the output of new products [6]. Hence, the spending on technical transformation is selected as an input factor of innovation activities. In terms of innovation performance indicators, patents and scientific papers are appropriate indicators of innovation performance for such innovation subjects as universities and research institutes; for high-tech companies, the sales revenue of new products is a more suitable indicator to evaluate innovation performance.

Based on the above analysis, as for the inputs of innovation activities, we select internal R\&D spending (X1), the FTE of R\&D personnel (X2) and the spending on technical transformation (X3) as the indicators of innovation input, with the sales revenue of new products (Y) selected as 
the indicator to gauge the innovation performance of hightech industries.

\section{B. Empirical Analysis}

By using the co-integration analysis method, this paper do an empirical analysis of China's high tech industry innovation input and innovation performance relationship, in accordance with the "unit root test-co-integration test - error correction model-Granger causality test" four steps ${ }^{[7]}$. In order to eliminate the heteroscedasticity, each index was taken the logarithm ${ }^{[6]}$, namely $\mathrm{LNX}_{1}=\log \left(\mathrm{X}_{1}\right), \mathrm{LNX}_{2}=\log$ $\left(\mathrm{X}_{2}\right), \mathrm{LNX}_{3}=\mathrm{Log}\left(\mathrm{X}_{3}\right), \mathrm{LNY}=\log (\mathrm{Y})$. The corresponding first order difference variables and two order difference variables are respectively $\mathrm{DLNX}_{1}, \mathrm{DLNX}_{2}, \mathrm{DLNX}_{3}, \mathrm{DLNY}$ and $\operatorname{DDLNX}_{1}, \mathrm{DDLNX}_{2}, \mathrm{DDLNX}_{3}, \mathrm{DDLNY}$ as shown in "Table I".

TABLE I. RAW DATA

\begin{tabular}{lllll}
\hline Year & $\begin{array}{c}\text { Internal R\&D Spending } \\
\text { (100million yuan) }\end{array}$ & $\begin{array}{c}\text { FTE of R\&D ersonnel } \\
\text { (10000 man-years) }\end{array}$ & $\begin{array}{c}\text { Technical Transformation Spending } \\
\text { (100million yuan) }\end{array}$ & $\begin{array}{c}\text { Sales Revenue of New Products } \\
\text { (100 million yuan) }\end{array}$ \\
\hline 2005 & 362.5 & 17.3 & 159 & 6915 \\
2006 & 456.4 & 18.9 & 171.9 & 8249 \\
2007 & 545.3 & 24.8 & 211 & 10303 \\
2008 & 655.2 & 28.5 & 218.6 & 12280 \\
2009 & 774 & 32 & 251.1 & 12595 \\
2010 & 967.8 & 39.9 & 268.7 & 16365 \\
2011 & 1440.9 & 51.1 & 304.7 & 22473 \\
2012 & 1733.8 & 62.3 & 368.9 & 25571 \\
2013 & 2034.3 & 67 & 425.7 & 31230 \\
2014 & 2274.3 & 70.1 & 374.5 & 35494 \\
2015 & 2626.7 & 72.7 & 400.9 & 41413 \\
\hline
\end{tabular}

1) $A D F$ Test: Using the ADF method, the above variables were tested separately, and the results were shown in "Table II".

TABLE II. ADF TEST RESULT

\begin{tabular}{lllllll}
\hline Variable & $\begin{array}{c}\text { ADF test } \\
\text { value }\end{array}$ & \multicolumn{1}{c}{$\begin{array}{c}\text { types of test } \\
(\mathbf{C}, \mathbf{T}, \mathbf{L})\end{array}$} & $\begin{array}{c}\mathbf{1 \%} \text { critical } \\
\text { value }\end{array}$ & $\begin{array}{c}\mathbf{5 \%} \text { critical } \\
\text { value }\end{array}$ & \multicolumn{1}{c}{$\begin{array}{c}\mathbf{1 0 \%} \text { critical } \\
\text { value }\end{array}$} \\
\hline LNX1 & -0.6267 & $(\mathrm{C}, \mathrm{T}, 3)$ & -5.8352 & -4.2465 & -3.5905 & non-stationary \\
DLNX1 & -0.5811 & $(\mathrm{C}, 0,3)$ & -4.8035 & -3.4033 & -2.8418 & non-stationary \\
DDLNX1 & -5.5901 & $(0,0,2)$ & -2.9372 & -2.0063 & -1.5981 & stationary \\
LNX2 & -1.3511 & $(\mathrm{C}, \mathrm{T}, 3)$ & -5.8352 & -4.2465 & -3.5905 & non-stationary \\
DLNX2 & -1.6290 & $(\mathrm{C}, 0,1)$ & -4.4206 & -3.2598 & -2.7711 & non-stationary \\
DDLNX2 & -8.0578 & $(0,0,0)$ & -2.8473 & -1.9882 & -1.6001 & stationary \\
LNX3 & -2.5949 & $(\mathrm{C}, \mathrm{T}, 2)$ & -5.5219 & -4.1078 & -3.5150 & non-stationary \\
DLNX3 & -2.0471 & $(\mathrm{C}, 0,1)$ & -4.4206 & -3.2598 & -2.7711 & non-stationary \\
DDLNX3 & -7.4869 & $(0,0,0)$ & -2.8473 & -1.9882 & -1.6001 & stationary \\
LNY & 1.3171 & $(\mathrm{C}, \mathrm{T}, 3)$ & -5.8352 & -4.2465 & -3.5905 & non-stationary \\
DLNY & 0.2931 & $(\mathrm{C}, 0,3)$ & -4.8035 & -3.4033 & -2.8418 & non-stationary \\
DDLNY & -4.1617 & $(0,0,2)$ & -2.9372 & -2.0063 & -1.5981 & stationary \\
\hline
\end{tabular}

The results show that the time series variables LNX1, LNX2, LNX3, LNY and their first order difference variables are non-stationary time series, but the second order difference variables are stationary time series. Thus, $\mathrm{LNX}_{1}$, $\mathrm{LNX}_{2}, \mathrm{LNX}_{3}, \mathrm{LNY}$ are two order single sequence.

2) Co-integration test: Integration test in this paper was used is EG two-step method, namely first respectively the $\mathrm{LNX}_{1}$ and LNY, $\mathrm{LNX}_{2}$ and $\mathrm{LNY}, \mathrm{LNX}_{3}$ and $\mathrm{LNY}$ of regression analysis, and then to the residual sequence $\left(\mathrm{E}_{1}, \mathrm{E}_{2}\right.$ and $\left.\mathrm{E}_{3}\right)$ stationarity test.
The long-term equilibrium equation of the $\mathrm{R} \& \mathrm{D}$ internal expenses and the new product sales revenue of the high-tech industry:

$$
\text { LNY=3.650306+0.885322*LNX1 }
$$

$$
\text { (23.44210) (32.81688) }
$$

R- squared $=0.990800 \quad \mathrm{DW}=1.467136$

The unit root test results of the residuals are shown in "Table III".

TABLE III. The Unit Root Test Results of E1

\begin{tabular}{lllllll}
\hline Variable & ADF test value & $\begin{array}{c}\text { Types of test } \\
(\mathbf{C}, \mathbf{T}, \mathbf{L})\end{array}$ & $\mathbf{1 \%}$ critical value & $\mathbf{5 \%}$ critical value & $\mathbf{1 0 \%}$ critical value & Results \\
\hline $\mathrm{E} 1$ & -1.7170 & $(0,0,2)$ & -2.8473 & -1.9882 & -1.6001 & stationary \\
\hline
\end{tabular}


The long-term equilibrium equation of the FTE of R\&D personnel and the new product sales revenue of the high-tech industry:

$\mathrm{LNY}=4.819874+1.378958 * \mathrm{LNX}_{2}$

\section{(12.15217) (9.957768)}

\section{R- squared $=0.908389 \quad \mathrm{DW}=1.052119$}

The unit root test results of the residuals are shown in "Table IV".

TABLE IV. The Unit Root Test Results of E2

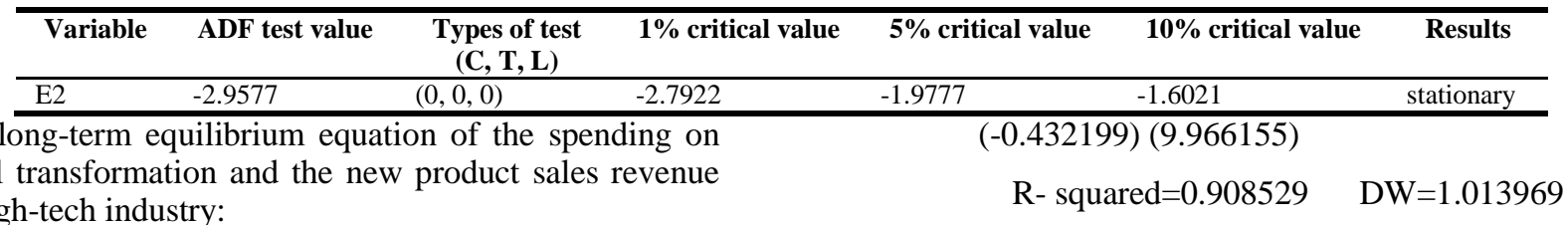

of the high-tech industry:

$\mathrm{LNY}=-0.396082+1.790958 * \mathrm{LNX}_{3}$
The unit root test results of the residuals are shown in "Table V".

TABLE V. The Unit Root Test Results of E3

\begin{tabular}{llccccc}
\hline Variable & ADF test value & $\begin{array}{c}\text { Types of test } \\
(\mathbf{C}, \mathbf{T}, \mathbf{L})\end{array}$ & $\mathbf{1 \%}$ critical value & $\mathbf{5 \%}$ critical value & $\mathbf{1 0 \%}$ critical value & Results \\
\hline E3 & -3.1669 & $(0,0,3)$ & -2.8861 & -1.9959 & -1.5991 \\
\hline
\end{tabular}

The results of co integration test show that there are longterm equilibrium of $\mathrm{LNY}$ and $\mathrm{LNX}_{1}, \mathrm{LNY}$ and $\mathrm{LNX}_{2}, \mathrm{LNY}$ and $\mathrm{LNX}_{3}$.

3) Error correction model: Using the non-equilibrium error which is the Lag phase residuals, error correction model was established. Three estimates can be obtained.

DLNY $=-3.19 \mathrm{E}-0.5+0.856927 * \mathrm{DLNX}_{1}-0.760468 * \mathrm{E} 1(-1)$

$$
(-0.000460) \quad(3.150301) \quad(-2.036946)
$$

R- squared $=0.562876 \quad \mathrm{DW}=1.840667$

DLNY $=0.233544-1.86221 * \mathrm{DLNX}_{2}-0.192722 * \mathrm{E} 2(-1)$

$$
\begin{array}{lll}
(4.837385) & (-0.598574) \quad(-1.127988)
\end{array}
$$

$\mathrm{R}$ - squared $=0.343558 \quad \mathrm{DW}=1.819714$

$\mathrm{DLNY}=0.147852+0.458927 * \mathrm{DLNX}_{3}-0.139659 * \mathrm{E} 3(-1)$

$$
\begin{array}{rl}
(3.687065) \quad(2.018783) & (-0.942627) \\
\text { R- squared }=0.337799 & \mathrm{DW}=2.178046
\end{array}
$$

Results of the error-correction model (ECM) show that:

- In the short term, the change in the sales revenue of new products in high-tech industries is influenced by the changes in internal R\&D spending, the FTE of R\&D personnel and the spending on technical transformation.

- E1 (-1), E2 (-1) and E3 (-1) are error-correction items. The coefficient reflects the mechanism of the ECM self-correcting the errors that deviate from equilibrium. When the correction coefficient is 1 , the innovation performance and input of high-tech industries can be adjusted to equilibrium in the next year. The coefficients of the model are -0.760468 , 0.192722 and -0.139659 respectively, suggesting that the equilibrium relationship between internal $R \& D$ funding and innovation performance has a strong correction ability of adjusting disequilibrium errors, while the other two correction abilities are weak; the coefficient is negative and in line with the correction mechanism.

4) Granger Causality Test: Using Grainger causality test to reveal the causality between the variables, the results are as "Table VI".

TABLE VI. RESUlts OF GRANGER CAUSALITY TEST

\begin{tabular}{llll}
\hline \multicolumn{1}{c}{ Variables } & $\begin{array}{c}\text { Variable } \\
\text { number }\end{array}$ & $\begin{array}{c}\text { F statistical } \\
\text { value }\end{array}$ & $\begin{array}{c}\text { Concomitant } \\
\text { probability }\end{array}$ \\
\hline $\begin{array}{l}\text { LNY doesn't } \\
\text { cause LNX }\end{array}$ & 11 & 10.1379 & 0.0129 \\
$\begin{array}{l}\text { LNX doesn't } \\
\text { cause LNY }\end{array}$ & 0.03687 & 0.8525 \\
$\begin{array}{l}\text { LNY doesn't } \\
\text { cause LNX }\end{array}$ & 11 & 5.01069 & 0.0556 \\
$\begin{array}{l}\text { LNX doesn't } \\
\text { cause LNY }\end{array}$ & & 1.59041 & 0.2428 \\
$\begin{array}{l}\text { LNY doesn't } \\
\text { cause LNX }\end{array}$ & 11 & 4.75670 & 0.0608 \\
$\begin{array}{l}\text { LNX doesn't } \\
\text { cause LNY }\end{array}$ & 0.36376 & 0.5631 \\
\hline
\end{tabular}

"Table VI" shows that, at the $95 \%$ confidence level, it can be accepted that LNY is the Granger cause the $\mathrm{INX}_{1}$, $1 N X_{1}$ is not the cause of LNY. At the $90 \%$ confidence level, it can be accepted that $\mathrm{LNY}$ is caused by $\mathrm{LNX}_{2}, \mathrm{INX}_{2}$ is not the cause of LNY. In the third test, $\mathrm{LNX}_{3}$ is not the cause of LNY, in $90 \%$ confidence level, it can be accepted that LNY is the Granger cause the $\mathrm{INX}_{3}$.

\section{CONCLUSION}

\section{A. Conclusions}

Results of the co-integration analysis suggest that the sales revenue of new products has a long-term equilibrium relationship with internal $R \& D$ spending, the FTE of $R \& D$ personnel and the spending on technical transformation. In 
other words, there is a long-term equilibrium relationship between the innovation input and performance of high-tech industries. From the perspective of the co-integration equation, every extra unit of internal R\&D spending, the FTE of R\&D personnel and the spending on technical transformation would increase the sales revenue of new products over the same period by $0.885322,1.378958$ and 1.790958 units respectively. In addition, in the short term, the change in the sales revenue of new products in high-tech industries are influenced by the changes in internal $R \& D$ spending, the FTE of R\&D personnel and the spending on technical transformation. In particular, the equilibrium relationship between internal $R \& D$ spending and sales revenue of new products has a strong correction ability of adjusting disequilibrium errors.

The Granger Causality Test results find that the sales revenue of new products leads to the changes in internal R\&D spending, the FTE of R\&D personnel and the spending on technical transformation. A possible explanation for such conclusions is: The improvement of corporate innovation performance boosts corporate development and revenue, making it possible for enterprises to further increase their R\&D investment and technical upgrade and input.

In Chinese high-tech industries, the change in the sales revenue of new products is not caused by the changes in internal R\&D spending, the FTE of R\&D personnel and the spending on technical transformation. The result seems not to match reality, possibly for the following reasons:

R\&D investment is usually high-risk investment with a long cycle. Therefore, many high-tech companies are more inclined to purchase mature technologies to manufacture new products. Besides, despite their growing attention to the impact of $\mathrm{R} \& \mathrm{D}$ investment on long-term corporate development, high-tech companies invest only a small of proportion on $R \& D$, making internal $R \& D$ spending have an insignificant impact on innovation performance.

As for the FTE of R\&D personnel, the development of high-tech industries require a large number of R\&D staff, which helps sustain the innovation capacity of industrial development and form certain economies of scale. Nevertheless, given the overall poor quality of personnel who works in Chinese high-tech industries, the input of R\&D staff is hardly able to meet the demands of industrial development. As a result, the input of R\&D staff has not achieved the desired effect.

As to the spending on technical transformation, such funding has always constituted an important part of investment in technical development in China. Despite its ability to realize technical innovation, technical transformation delivers a relatively small value of achievements, thus having an insignificant impact on innovation performance.

\section{B. Suggestions}

1) Increasing $R \& D$ spending and improving the incentive mechanism: $\mathrm{R} \& \mathrm{D}$ spending is the key to the progress of science and technology. R\&D staff is the subject of technical innovation. Therefore, it is necessary to increase $\mathrm{R} \& \mathrm{D}$ spending and improve the incentive mechanism to boost corporate innovation performance. In terms of incentive mechanisms, $R \& D$ staff should be offered a good environment for scientific and technological innovation with incentive measures carried out in remuneration, performance evaluation, corporate culture and training to improve the staff's job satisfaction, initiative and creativity.

2) Increasing investment in technical transformation and improving the level of technical transformation: Technical transformation is an important means to help translate technical innovation achievements into productivity to realize their value [8]. Technical transformation also serves as a crucial component and approach in the technical innovation system. While boosting the fund in technical transformation, high-tech enterprises should work to improve the content of science and technology in technical transformation, with a focus on the application and conversion of technical achievements. Such enterprises should also combine introduction with digestion, absorption and innovation, seek import substitution, enhance their technical development capacity and constantly upgrade the level of technical transformation so as to improve the innovation performance of high-tech industries.

\section{ACKNOWLEDGMENT}

This work was supported by Liaoning Provincial Social Sciences Foundation 2013 (No. L13BJY030) and Economic and Social Development Foundation of Liaoning Province (No. 2016lslktglx-02).

\section{REFERENCES}

[1] He Qingfeng. The Relationship among Direct Human-capital Investment, R\&D Investment and Innovation Performance - An Empirical Research Based on the Panel Data of Science and Technological Activities in China [J]. Technology Economics, 2009 (4): 1-9.

[2] Sun Wei, Cheng Liwei and Liu Dong. Differences in the Variations of $\mathrm{R} \& \mathrm{D}$ Input and Technical Innovation Performance among Different Subjects [J]. Journal of Shanxi Finance and Economics University, 2009 (10): 64-70.

[3] Li Hui and Ma Yue. The Impact of R\&D Funding on Innovation Performance - A Panel Co-integration Analysis Based on High-tech Industries [J]. Journal of Northeast Normal University (Philosophy and Social Science), 2009.241-243Xu Juan. Research on Relative Efficiency Evaluation of Innovation Input in Various Universities [J]. Tsinghua Journal of Education 2009, 30(2): 76-80.

[4] Zhu Weiping and Lun Rui. An Empirical Analysis of the Correlation between Technical Input and Performance of High-tech Enterprises [J]. Science and Technology Management Research, 2004 (5):7-9.

[5] Cheng Hua. A Comparative Study of Facilitating Corporate R\&D by Direct Funding and Tax Breaks [J]. Forum on Science and Technology in China, 2006 (3): 56-59.

[6] Guan Jiancheng and Chen Kaihua. Measuring the Technica Innovation Efficiency of Chinese High-tech Industries [J]. Journal of Quantitative \& Technical Economics, 2009 (10):19-33.

[7] Wang Heling. Co-integration Analysis and its Applications [D] Xinjiang: Xinjiang University, 2005. 
[8] Tong Zongqing. Difficulties and Measures of Corporate Technical Transformation and Innovation [J]. Jiangnan Forum, 2003 (3): 32-33. 